\title{
Total Electron Content Obtained by Using the Global Positioning System
}

\author{
JANN YENQ LIU ${ }^{1}$, HO FANG TSAI ${ }^{1}$ and TING KUO JUNG ${ }^{1}$ \\ (Manuscript received 30 October 1995. in final form 30 January 1996)
}

\begin{abstract}
A procedure is introduced to obtain the balance of measurements of differential group delays and differential carrier phase lead characteristics, both phenomena being due to the ionospheric total electron content (TEC) along the ray path from a Global Positioning System (GPS) satellite. It has been demonstrated that utilizing the measurement of both pseudorange and carrier phase recorded by genetic GPS receivers, the precision of the vertical TEC derived when the anti-spoofing (AS) is on can be as good as that derived when it is off. Combining the data of a network of four GPS receivers, a TEC map is reconstructed which can be employed to examine the ionospheric latitude/longitude structure and dynamics in the Taiwan area.
\end{abstract}

(Key words: Global Positioning System, Total Electron Content, Ionosphere)

\section{INTRODUCTION}

The Global Positioning System (GPS) consists of 24 satellites, evenly distributed in 6 orbital planes around the globe at an altitude of about $20200 \mathrm{~km}$. The observables depend on the satellite-receiver distance, tropospheric/ionospheric effects, satellite and receiver clock offsets, phase ambiguities as well as satellite and receiver instrumental biases. There will be a bias for each of the two GPS frequencies $\left(f_{1}=1575.42 \mathrm{MHz}\right.$ and $\left.f_{2}=1227.60 \mathrm{MHz}\right)$ and their difference, henceforth referred to as differential instrumental bias, produces systematic instrumental errors in the estimates of ionospheric delays. If accurate estimates of the ionospheric total electron content (TEC) are to be obtained, these differential instrumental biases must be removed (Sardon et al., 1994).

Many scientists have carried out investigations on ionospheric TEC estimations. On the basis of their analysis of data from a single station, Lanyi and Roth (1988) and Coco et al. (1991), represented the vertical TEC by a polynomial. Wilson et al. (1992) used data from a global network of GPS stations to model the vertical TEC by spherical harmonics. Sardon et al. (1994) applied a Kalman filtering technique and obtained a precise estimation

1 Institute of Space Science or Center for Space and Remote Sensing Research, National Central University, Chung-Li, Taiwan, R.O.C. 
of both the instrumental biases as well as the TEC. Now, due to the recent developments in signal processing techniques, the TEC can be directly derived by a GPS ionospheric receiving system which is called the TECMETER. In view of these developments, the study presented in this paper determines the differential instrumental biases of general purpose GPS receivers in the Taiwan area by data obtained from a TECMETER at Lunping $\left(25.00^{\circ} \mathrm{N}, 121.16^{\circ} \mathrm{E}\right)$. The calibrated measurements with/without anti-spoofing systems being active are further compared with the ionospheric parameter of foF 2 recorded at the Chung-Li Ionospheric Station $\left(24.95^{\circ} \mathrm{N}, 121.23^{\circ} \mathrm{E}\right)$ for various seasons of 1994 . Then, combining all the data recorded by the GPS network, the true overhead TEC is derived, the diumal variation of the equatorial anomaly is examined, and finally the latitude/longitude TEC map of the Taiwan area is constructed.

\section{METHODOLOGY}

The propagation of GPS signals is affected by both the environment and instruments. Therefore, GPS pseudorange $p_{k j}^{i}$ and carrier phase $L_{k j}^{i}$ for frequencies 1 and 2 , in range units, can be expressed as follows:

$$
\begin{aligned}
& p_{1 j}^{i}=s_{0 j}^{i}+d_{\text {ion } 1 j}^{i}+d_{\text {trop } j}^{i}+c\left(\tau^{i}-\tau_{j}\right)+d_{q 1}^{i}+d_{q 1 j}+d_{\text {res } j}^{i}, \\
& p_{2 j}^{i}=s_{0 j}^{i}+d_{\text {ion } 2 j}^{i}+d_{\text {trop } j}^{i}+c\left(\tau^{i}-\tau_{j}\right)+d_{q 2}^{i}+d_{q 2 j}+d_{\text {res } j}^{i}, \\
& L_{1 j}^{i}=\lambda_{1} \phi_{1 j}^{i}=s_{0 j}^{i}-d_{\text {ion } 1 j}^{i}+d_{\text {trop } j}^{i}+c\left(\tau^{i}-\tau_{j}\right)-\lambda_{1} b_{1 j}^{i}, \\
& L_{2 j}^{i}=\lambda_{2} \phi_{2 j}^{i}=s_{0 j}^{i}-d_{\text {ion } 2 j}^{i}+d_{\text {trop } j}^{i}+c\left(\tau^{i}-\tau_{j}\right)-\lambda_{2} b_{2 j}^{i},
\end{aligned}
$$

The subscripts $i$ and $j$ represent the satellite and ground-based GPS receivers, respectively, $s_{0}$, the true distance between the receiver and satellite;

$d_{\text {ion }}, d_{\text {trop }}$, the ionospheric and tropospheric effects;

$c$, the speed of light in free space;

$\tau$, the satellite or receiver clock offset;

$d_{q}$, the instrumental bias of the satellite or receiver;

$d_{\text {res }}$, other bias;

$\lambda$, the carrier wavelength;

$\phi$, the total carrier phase between the receiver and satellite, and

$b$, the cycle slips of the carrier phase.

The ionosphere acts as a dispersive medium for the GPS signals, but the troposphere is nondispersive. As such the tropospheric effect in the carrier phase and pseudorange can be removed by subtracting (la) from (lb) and (lc) from (ld), respectively. According to 
the Appleton formula (for an example see Budden, 1985) the phase refractive index $n$ in the ionosphere is a function of the radiowave frequency, electron concentration (or plasma frequency), collision frequency and geomagnetic field strength (or gyrofrequency). In fact, however the GPS radiowave and plasma frequencies are much greater than the other two. Hence, the ionospheric effect in terms of the total electron content along a line-of-sight, $T E C^{*}$ in electron $/ \mathrm{m}^{2}$, between ground receiver $R_{x}$ and the satellite $T_{x}$ can be written as:

$$
d_{i o n}=s^{\prime}-s_{\bullet}=\int_{T_{x}}^{R_{x}}\left(\frac{1}{n}-1\right) d l=\frac{40.3}{f^{2}} \int_{T_{x}}^{R_{x}} N d l=\frac{40.3}{f^{2}} T E C^{*}
$$

where $s^{\prime}$ is the virtual distance between the receiver and satellite, $N$ is the electron concentration in electron $/ \mathrm{m}^{3}$, and $f$ represents radiowave frequency in $\mathrm{Hz}$. The $l$-axis stands for the satellite-to-receiver direction. Combining (1) and (2) yields:

$$
\begin{aligned}
T E C^{*} & =\frac{1}{40.3}\left(\frac{f_{1}^{2} f_{2}^{2}}{f_{1}^{2}-f_{2}^{2}}\right)\left(p_{2 j}^{i}-p_{1 j}^{i}-k^{i}-k_{j}\right), \text { and } \\
T E C^{*} & =\frac{1}{40.3}\left(\frac{f_{1}^{2} f_{2}^{2}}{f_{1}^{2}-f_{2}^{2}}\right)\left(\lambda_{1} \phi_{1 j}^{i}-\lambda_{2} \phi_{2}^{i} j+A_{j}^{i}\right),
\end{aligned}
$$

where $k^{i}=d_{q 2}^{i}-d_{q 1}^{i}, k_{j}=d_{q 2 j}-d_{q 1 j}$ and

$$
A_{j}^{i}=\left(p_{2 j}^{i}-p_{1 j}^{i}\right)+\left(\lambda_{2} \phi_{2 j}^{i}-\lambda \phi_{j}^{i}-\left(k^{i}-k_{j}\right) .\right.
$$

Wilson et al. (1992) and Sardon et al. (1994) found $k^{i}$ to be about 2-3 nanoseconds which is as small as $8 \times 10^{16}$ electron $/ \mathrm{m}^{2}$. Nevertheless, two tables given by Wilson et al. (1992) and Sardon et al. (1994) were employed to redeem the bias of $k^{i}$. To determine $k_{j}$, Tsai (1995) applied (3) to the measurements from a genetic GPS receiver to obtain the $T E C^{*}$ and then compared it with the simultaneous data recorded by the local TECMETER during 0400-0500LT (Ezquer et al., 1992). In doing so, he found that the value of $k_{j}$ of each GPS receiver is nearly a constant. Although (3) can solely and directly derive the TEC, due to the length of the pseudo code, the precision of the $T E C^{*}$ is relatively low. The alternative way is to combine (3) and (4) to obtain the least-square-fit value of $A_{j}^{i}$, and then to utilize (4) to attain greater precision of the $T E C^{*}$.

As a satellite passes from the horizon to zenith, the $T E C^{*}$ can be obtained. However, scientists have found that it is useful to mathematically adjust the $T E C^{*}$ to the TEC observed at the subionospheric point which is referred to as the vertical total electron content, VTEC:

$$
V T E C=T E C^{*} S(e) .
$$

In (6), $S(e)$ is the slant function given by Sover and Fanselow (1987):

$$
S(e)=\frac{1}{h_{1}-h_{2}}\left(\sqrt{R^{2} \sin ^{2}(e)-R^{2}+\left(R+h_{1}\right)^{2}}-\sqrt{R^{2} \sin ^{2}(e)-R^{2}+\left(R+h_{2}\right)^{2}}\right),
$$


where $e$ is the satellite elevation, $h_{1}$ and $h_{2}$ are the lower and upper heights of the ionosphere, respectively and $R$ is the mean radius of the Earth. It should be noted that the function $S$ basically depends on the height of the mean layer of the ionosphere, $h_{m}=\left(h_{1}+h_{2}\right) / 2$. Davies [1990] indicated that $h_{m}$ could lie between 300 and $450 \mathrm{~km}$, while HolfmannWellenhof et al. [1992] considered it should be limited between 300 and $400 \mathrm{~km}$. For simplicity, Sardon et al. (1994) assumed the $h_{m}$ to be $355 \mathrm{~km}$. Based on the results in Wu (1992), the present authors find the $h_{m}$ in the Taiwan area during 1993 and 1994 to be about $325 \mathrm{~km}$. Assuming there to be a network of 4 ground receivers and a full GPS constellation, 20-32 VTECs can be derived simultaneously (5-8 each ground site). Accordingly, such a network can ultimately be capable of making a "snapshot" of the longitudinal/latitudinal TEC distribution in the Taiwan area, thereby constructing the TEC map.

\section{EXPERIMENTS AND RESULTS}

Measurements from a network of four genetic GPS receivers, which are located at Fonglin $\left(23.60^{\circ} \mathrm{N}, 121.45^{\circ} \mathrm{E}\right)$, Yang-Ming-Shan $\left(25.02^{\circ} \mathrm{N}, 121.57^{\circ} \mathrm{E}\right)$, Kinmen $\left(24.32^{\circ} \mathrm{N}\right.$, $\left.118.39^{\circ} \mathrm{E}\right)$, and Kending $\left(21.82^{\circ} \mathrm{N}, 120.78^{\circ} \mathrm{E}\right)$, have been used to monitor the TEC in the Taiwan area (see Figure 1). A decrease in an elevation angle generally increases occurrences of the cycle slip and other unwanted noises. Therefore, to avoid such a complexity, the cut-off elevation angle in this study is set to be $10^{\circ}$. The instrumental biases of four genetic GPS receivers were determined by comparing their $T E C^{*}$ with the one obtained by the TECMETER during 0400-0500LT for many days in 1994 (see Table 1). It is important to note that two different GPS receivers were used before/after July 27, 1994, and therefore the instrumental bias in Yang-Ming-Shan has two values.

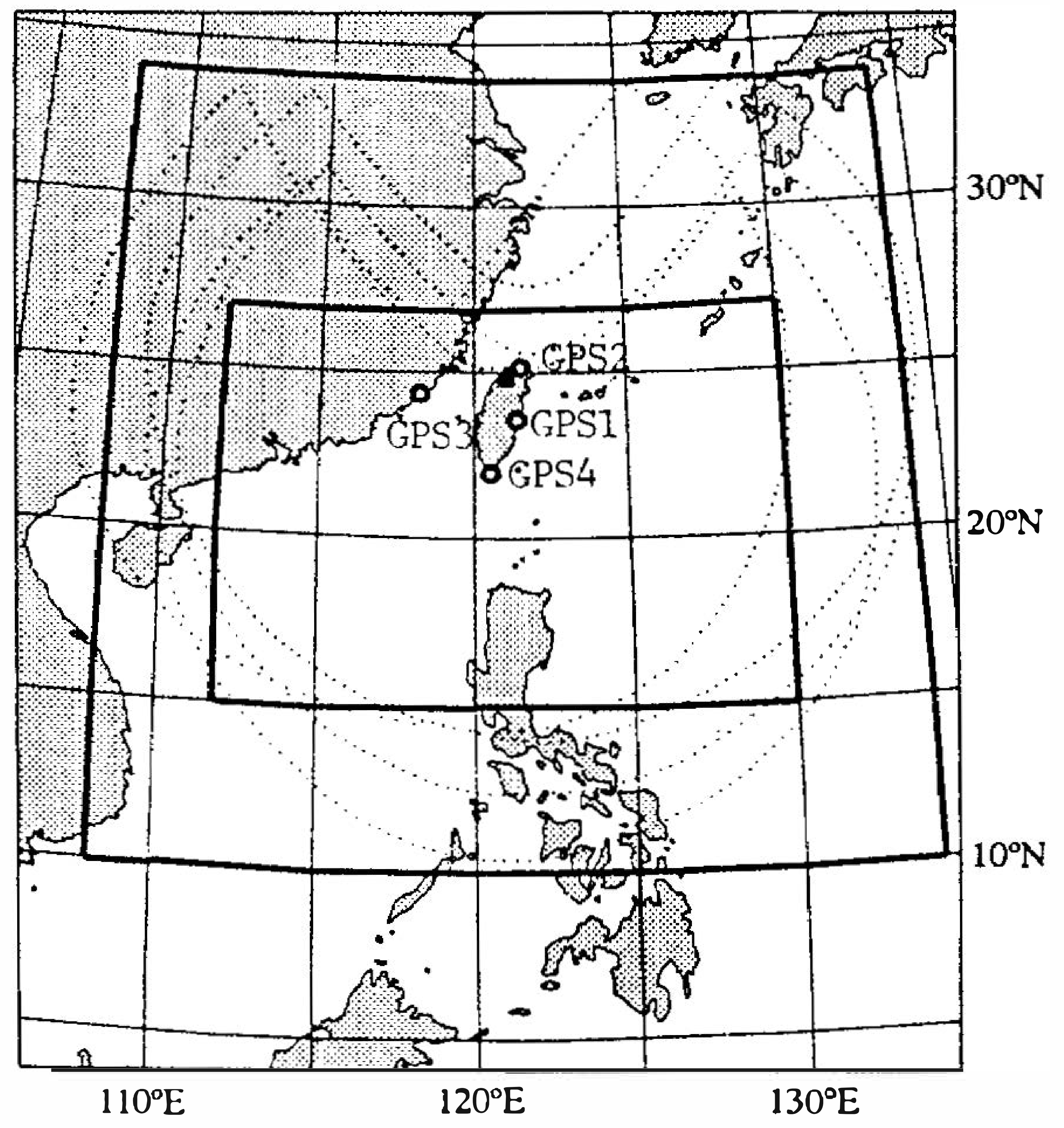

Fig. 1. Location of the GPS sites and their ionospheric coverage. The open circles represent the location of GPS receivers. The small and large frames, obtained by and represent the coverages of the high precision (interpolated) and low precision (extrapolated) TEC maps. 
Table 1. The instrumental biases of the network of four GPS receivers in 1994.

\begin{tabular}{lllc}
\hline \multicolumn{2}{l}{ Site Number/Name } & Geographic Location & Receiver Bias $k_{j}(\mathrm{~ns})$ \\
\hline \hline GPS1 & Fonglin & $23.60^{\circ} \mathrm{N}, 121.45^{\circ} \mathrm{E}$ & $-5.6 \pm 0.1$ \\
GPS2 & Yang-Ming-Shan & $25.02^{\circ} \mathrm{N}, 121.57^{\circ} \mathrm{E}$ & $-5.9 \pm 3.6-3.7 \pm 0.2$ \\
GPS3 & Kinmen & $24.32^{\circ} \mathrm{N}, 118.39^{\circ} \mathrm{E}$ & $-1.9 \pm 0.5$ \\
GPS4 & Kending & $21.82^{\circ} \mathrm{N}, 120.78^{\circ} \mathrm{E}$ & $-2.6 \pm 0.4$ \\
\hline
\end{tabular}

Figure 2a shows the $V T E C$ of December 17, 1993 obtained by applying the slant function shown by (7) on measurements from the TECMETER at Lunping. Figures $2 b$ and 2c show the VTECs of the same day derived by applying (3) and (4), respectively, on measurements recorded at Fonglin. It is clear that the curves in Figure $2 \mathrm{c}$ are cleaner and smoother than those in Figure $2 \mathrm{~b}$ which indicates that (4) yields a VTEC with greater precision. In fact, the quality of the $V T E C$ derived by (4) can be more clearly revealed by examining the difference of TEC values presented in Figures $2 \mathrm{a}$ and $2 \mathrm{c}$ at 0500LT (which is about $10-20 \%$ of the TEC at $0500 \mathrm{LT}$ ). If the calibration value (the instrumental bias) from the TECMETER is used, the error would be lower than $2 \%$ during the daytime hours.
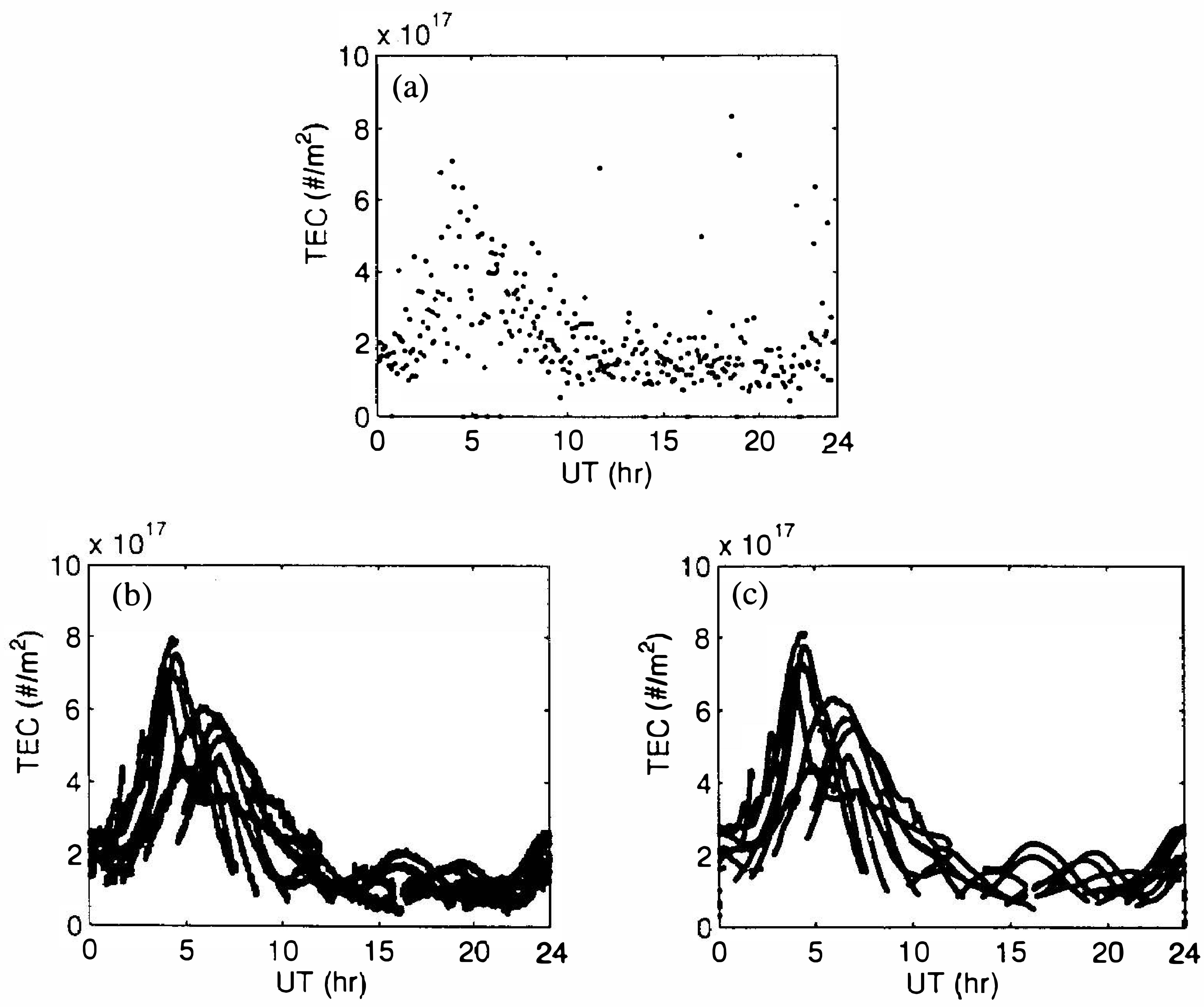

Fig. 2. Vertical TEC (a) recorded by the TECMETER at Lunping, (b) derived by using pseudorange measurements obtained at Fonglin, (c) derived by using pseudorange/phase measurements obtained at Fonglin, on December 17, 1993 (AS off). 
Nevertheless, the similarities among Figures $2 \mathrm{a}, 2 \mathrm{~b}$ and $2 \mathrm{c}$ demonstrate that measurements from genetic GPS receivers can be successfully employed to derive ionospheric TEC value.

On 31 January 1994, the long-anticipated anti-spoofing (AS) was finally implemented and, instead of $\mathrm{P}$-codes $\left(\mathrm{P}_{1}\right.$ and $\left.\mathrm{P}_{2}\right)$, only $\mathrm{C} / \mathrm{A}$ and $\mathrm{P}_{2}$ were accessible. Hofmann-Wellenhof et al. (1992) concluded that the precision of a pseudorange derived from code measurements has traditionally been about $1 \%$ of the chip length. Therefore, a precision of roughly $3 \mathrm{~m}$ and 0.3 meter is achieved with a C/A and P-code pseudorange, respectively. Consequently, it is expected that when the AS is active, the precision of the $V T E C$ becomes significantly low (see the difference between Figures $2 b$ and $3 a$ ). Fortunately, with the application of (4), the precision of the $V T E C$ derived when the AS is on can be as clean and smooth as that derived during the AS off (see, Figures $2 \mathrm{c}$ and $3 \mathrm{~b}$, for comparison).
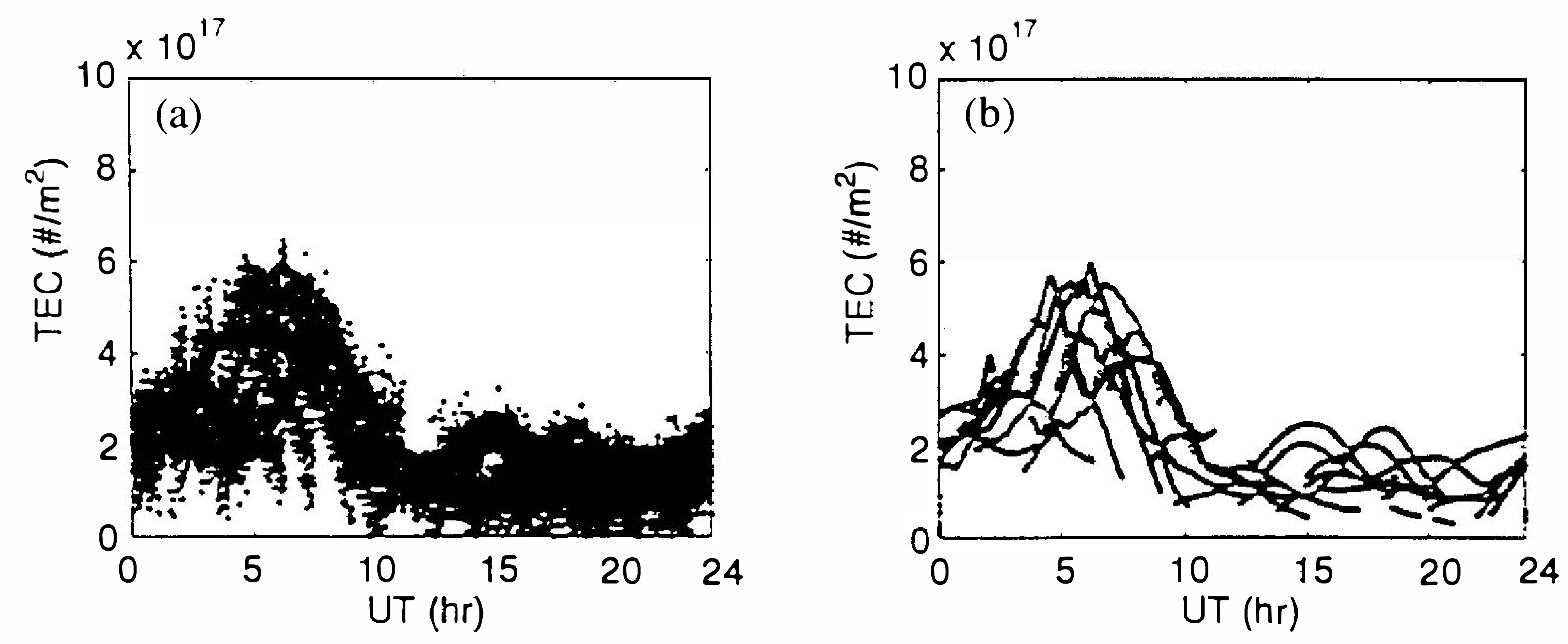

Fig. 3. Vertical TEC obtained (a) by using pseudorange measurements, (b) by using pseudorange/phase measurements, at Fonglin on December 21, 1994 (AS on).

Figures 4a-d illustrate the $V T E C$ obtained from the GPS receiver located at YangMing-Shan along with the maximum plasma frequency $f o F 2$ observed by the ionosonde at the ionospheric Chung-Li Station near the equinoxes and solstices of 1994. Both the VTEC and foF 2 yield the smallest values during the daytime of the summer solstice, reach the greatest values between 0800 and 1200UT in the spring equinox but otherwise, generally, show very similar tendencies through various seasons.

Since the GPS satellites are evenly distributed in 6 orbital planes, it is possible to adopt all the data of a GPS network to construct the TEC map. The coverage of the map is a function of the GPS satellites' orbit, the cut-off elevation angle and the altitude of the subionospheric point. Figures 5a-c illustrate the ionospheric footprints of the GPS satellites observed from Yang-Ming-Shan at various subionospheric altitudes and cut-off elevation angles. Both the higher altitude and the smaller angle yield the larger coverage, and the coverage is not symmetric in the north-south direction. In this study, the elevation angle $e \geq 10^{\circ}$ and the height of the mean layer of the ionosphere $h_{m}=325 \mathrm{~km}$. The coverage of each GPS receiver and the combining coverage of the four receivers are respectively indicated by dashed lines and solid-line frames in Figure 1. 

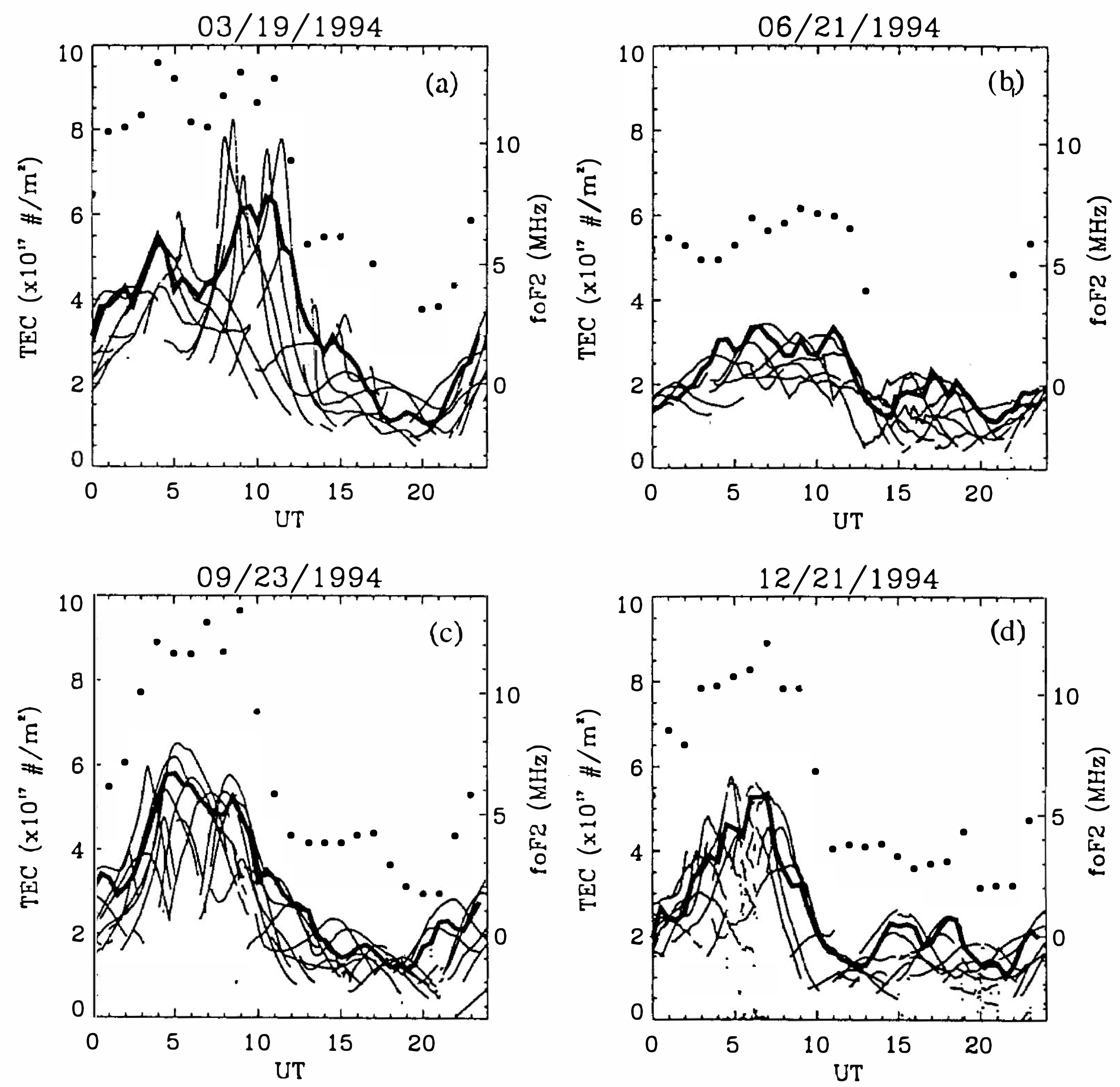

Fig. 4. A comparison between the vertical TEC derived from the GPS receiver at Yang-Ming-Shan and the maximum plasma frequency $f o F 2$ in the ionosphere measured at the ionospheric Chung-Li station on (a) March 19, (b) June 21, (c) September 23, and (d) December 21, 1994. Solid circles represent foF2. Thin solid lines are the vertical TEC derived from various satellites, and the heavy solid lines are the vertical .TEC at the ionospheric Chung-Li station derived from TEC maps.

Figures 6a-h represent the midday and midnight TEC maps for various seasons of the year 1994, and they show that at midday (1200LT) the TECs have large values and gradients with the maximums locating around $118-119^{\circ} \mathrm{E}, 20-24^{\circ} \mathrm{N}$. At midnight (0000LT), the values and the gradients of the TECs become small. The dashed lines and solid triangles represent the longitude and location of the Chung- $\mathrm{Li}$ ionospheric station. If the data along the longitude are extracted from a sequence of TEC maps, the distribution of latitudinal TEC vs time can be obtained. Figures $7 \mathrm{a}-\mathrm{d}$ reveal that the maxima of the TEC, signatures of the equatorial anomaly, generally appear around 1300LT. The other maximum in the TEC, found near 

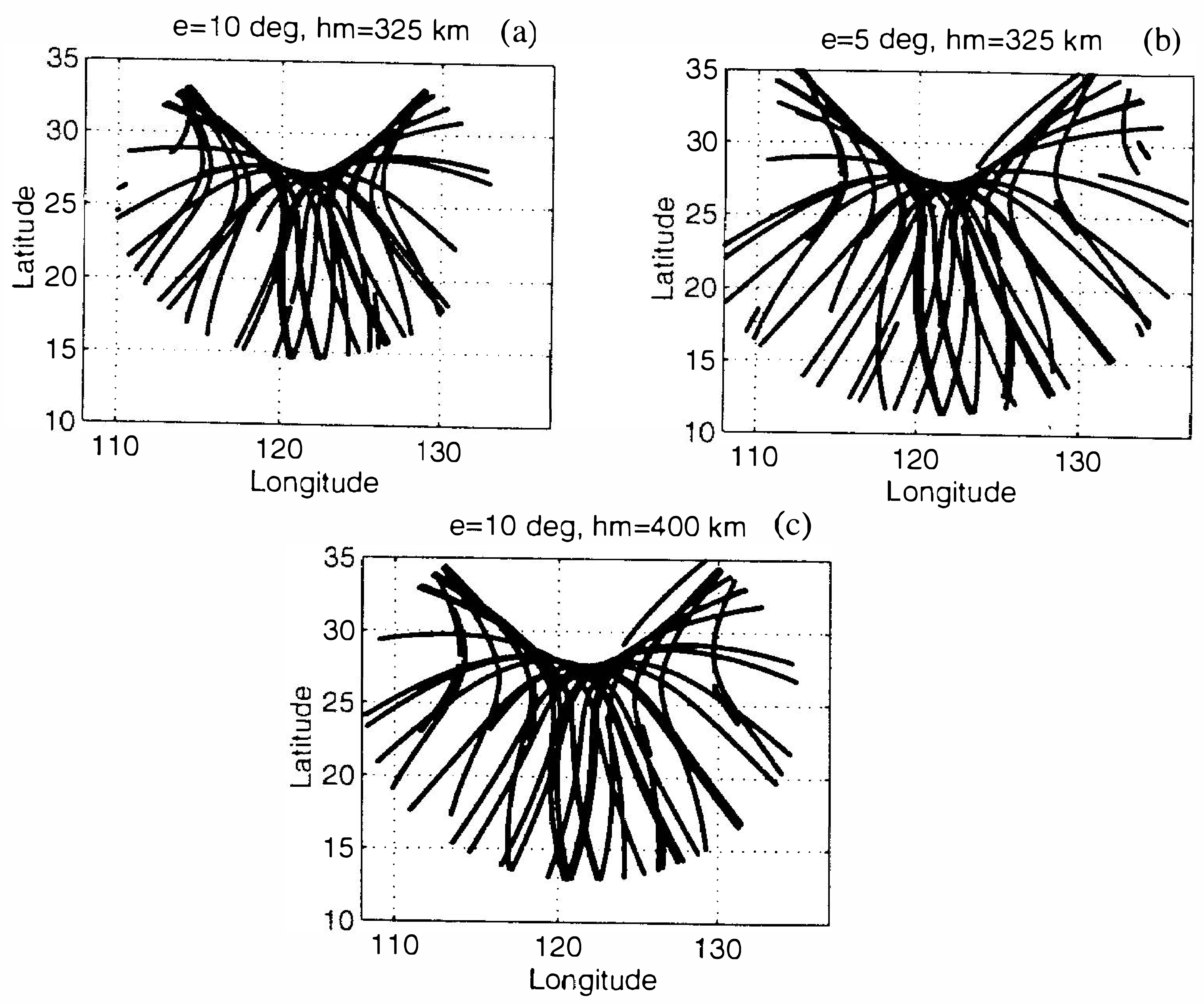

Fig. 5. Satellite foot prints on the subionosphere observed with the elevation angle and the subionospheric point altitude pairs of (a) $\left(10^{\circ}, 325 \mathrm{~km}\right)$, (b) $\left(5^{\circ}\right.$, $325 \mathrm{~km})$, and (c) $\left(10^{\circ}, 400 \mathrm{~km}\right)$.

1800LT around $15^{\circ} \mathrm{N}$ on March 19, 1994, may have been caused post sunset enhancement. These figures are also compared with the results obtained by the Navy Navigation Satellite System (NNSS) at Lunping, and it is found that the two systems generally yield an excellent agreement (Lunping Observatory, private communication, 1995). Additionally, interpolating the values of the solid triangles from a sequence of TEC maps, the VTEC at the Chung-Li ionospheric station can be obtained (see the heavy solid curves in Figure 4).

\section{DISCUSSION AND CONCLUSIONS}

Although the two pseudoranges can be solely applied to derive the TEC, during the AS on-period such a technique may yield results which significantly suffer from low precision with the C/A code. This paper provides a procedure to derive the ionospheric TEC from pseudoranges and carrier phases of the two frequencies recorded by genetic GPS receivers. The similar tendencies in $f_{O} F 2$ and the $V T E C$ indicate that the maximum electron density $N_{m}$ of the ionosphere dominates the value of the $V T E C$. A good agreement among the $V T E C$, measurements from the TECMETER and $f_{o F}$ confirms that utilizing measurements of pseudoranges and carrier phases recorded by genetic GPS dual-frequency receivers constantly yield high precision in the TEC. 
Liu et al.
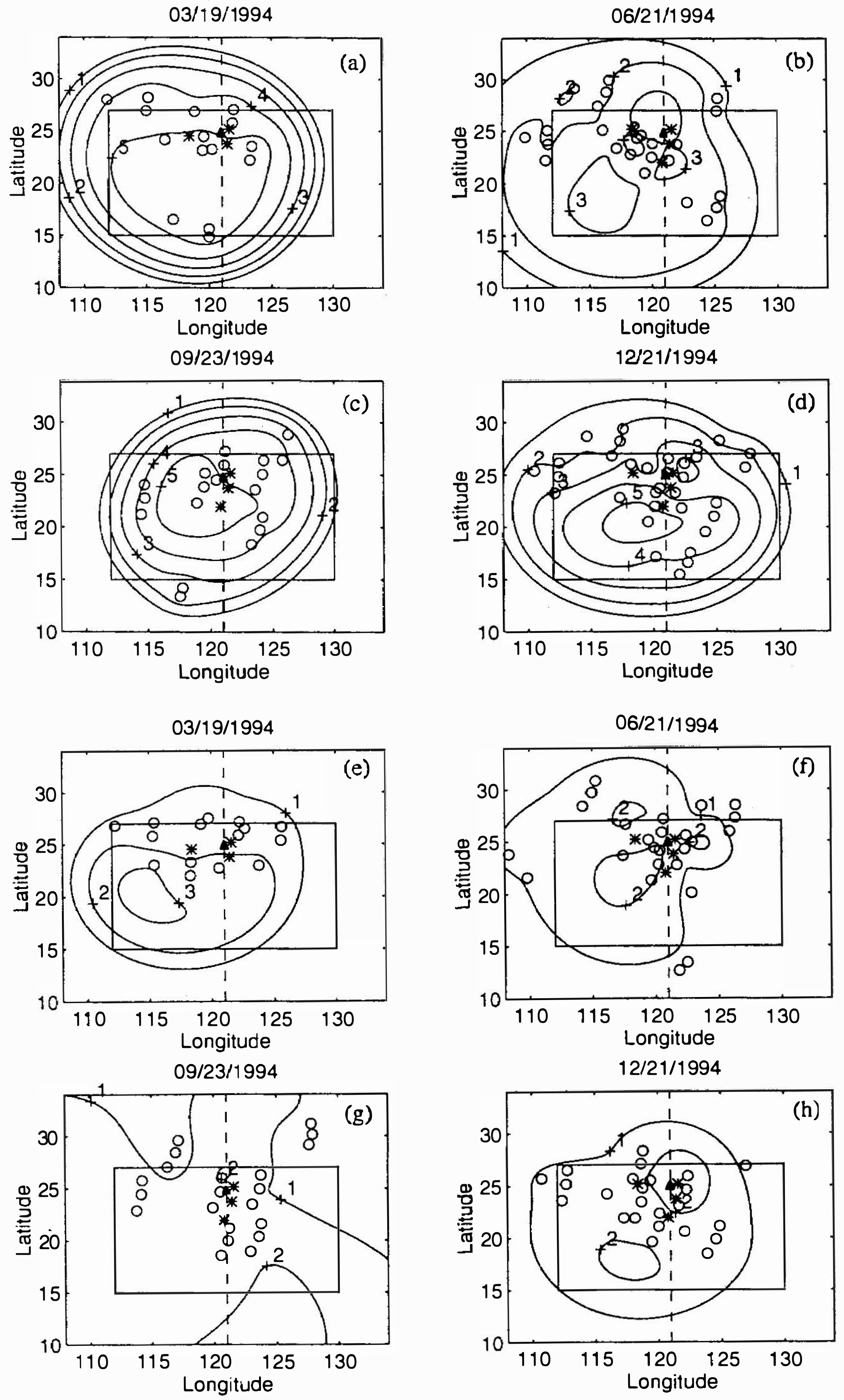

Fig. 6. Midday (a)-(d) and midnight (e)-(h) TEC maps respectively obtained on Marçh 19, June 21, September 23, and December 21, 1994. 

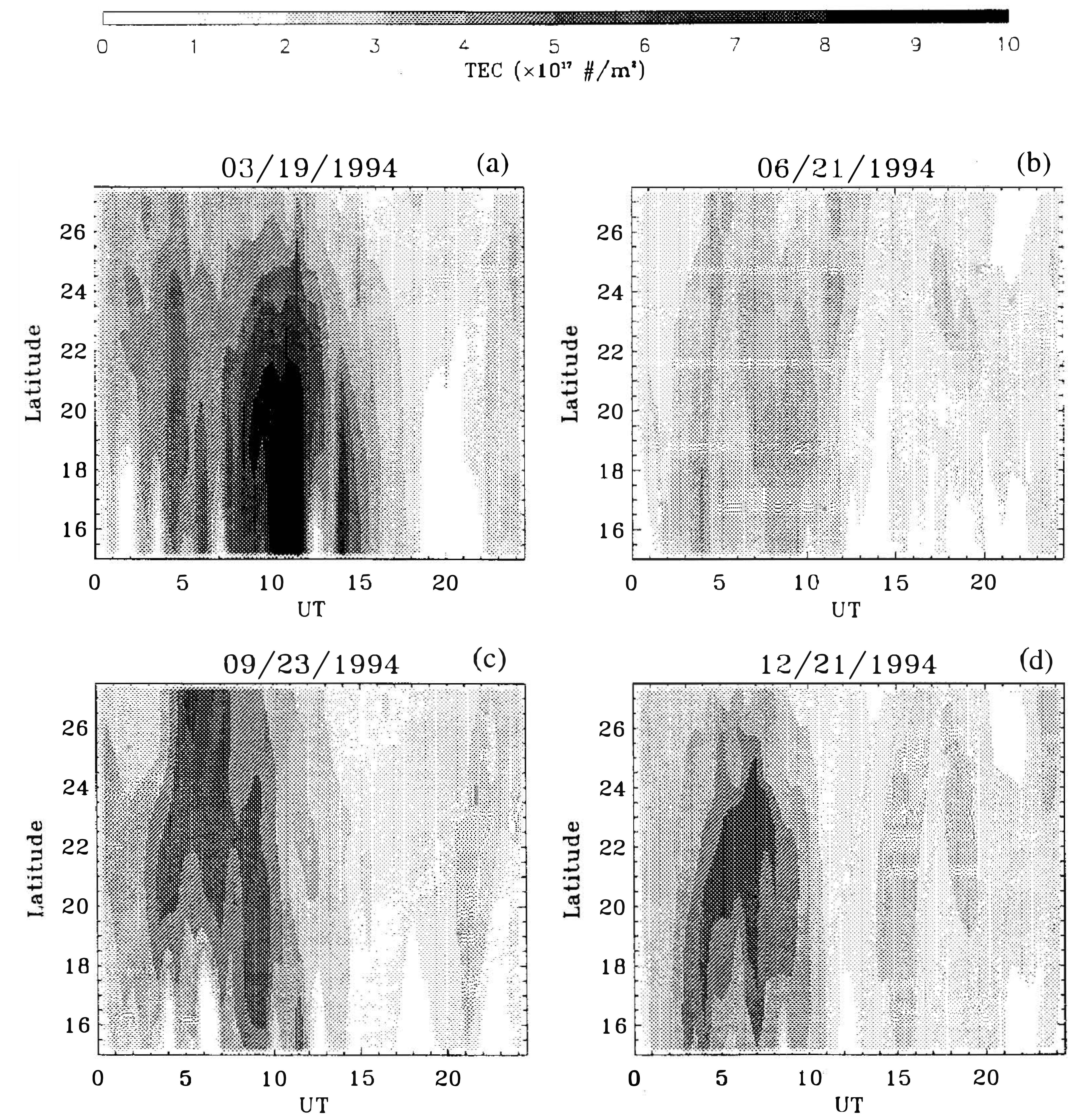

Fig. 7. Diurnal variation in latitudinal distribution of the vertical TEC on (a) March 19, (b) June 21, (c) September 23, and (d) December 21, 1994.

Incorporating measurements of a network of 4 GPS receivers, TEC maps are constructed, which can be employed to monitor the longitudinal/latitudinal structures and dynamics of the ionosphere in the Taiwan area. Since satellites do not constantly appear in zenith, the best way to remove the longitudinal, latitudinal and local time effects to obtain the $V T E C$ at a specific location is to interpolate from a TEC map. A similar technique can also be applied to obtain the latitudinal TEC variation vs time which is suitable for examining the evolution of the TEC caused by equatorial anomaly.

The curves of the VTEC reveal that for diurnal variations, the maximum and minimum generally appear during 1200-1300LT (0400-0500UT) and during 0400-0500LT (20002100UT), respectively, iwhild as for the seasonal variations, the TEC in summer yields a small value. The TEC maps obtained in this article also show that TEC gradients in daytime 
are greater than those in nighttime. Moreover, in view of the TEC diurnal variations and the gradients in the TEC maps, in order to minimize the ionospheric effect, it is suggested that the GPS application of the single frequency rapid static surveying between post midnight and priori dawn.

Acknowledgement This research has been partially supported by National Science Council of ROC Grants NSC84-2612-M-008-003-AP5 and NSC85-2612-M-008-006 to National Central University. The authors would like to express appreciation to professor J. Wu at Center for Space and Remote Sensing Research of National Central University for his weful suggestions. The authors wish to thank the ministry of interior for supplying GPS measurements and the Lunping Observatory for providing ionospheric foF 2 and TECMETER data. The authors thank the revirws and the editors for useful suggestions that greatly improve the presentation of this paper.

\section{REFERENCES}

Budden, K. G., 1985: The Propagation of Radio Waves, Cambridge University Press, New York, 669pp.

Coco, D. S., C. Cokes, S. R. Dahlke, and J. R. Clynch, 1991: Variability of GPS satellite differential group delay biases. IEEE Trans. Aerosp. Electron. Syst., 27, 931-938.

Davies, K., 1990: Ionospheric Radio, Peter Peregrinus Ltd., 580pp.

Ezquer, R. G., N. O. Adler, S. M. Radicella, M. M. Gonzalez, and J. R. Manzano, 1992: Total electron content obtained from ionogram data alone. Radio Sci., 27, 429-434.

Hofmann-Wellenhof, B., H. Lichtenegger, and J. Collins, 1992: GPS theory and practice, Springer-Verlag, Wien, New York, 326pp.

Lanyi, G. E., and T. Roth, 1988: A comparison of mapped and measured total ionospheric electron content using the Global Positioning System and beacon satellites. Radio Sci., 23, 483-492.

Sardon, E., A. Rius, and N. Zarraoa, 1994: Estimation of the transmitter and receiver differential biases and the ionospheric total electron content from Global Positioning System observations. Radio Sci., 29, 577-586.

Sover, O. J., and J. L. Fanselow, 1987: Observation model and parameter partials for the JPL VLBI parameter estimation software MASTERFIT-1987. Jet Propulsion Lab. Publ., 83-39, Rev. 3, 1-60.

Tsai, H. F., 1995: Total Electron Content Obtained by using the Global Positioning System, MS thesis, National Central University, Taiwan, ROC, 84pp.

Wilson, D. B., A. J. Mannucci, C. D. Edwards, and T. Roth, 1992: Global ionospheric maps using a global network of GPS receivers, the Int'l Beacon Satellite Symposium, MIT, Cambridge, MA, July 6-12.

Wu, S. L., 1992: Electron density profiles in Taiwan, MS thesis, National Central University, Taiwan, ROC, 83pp. 